\title{
DYNAMIC MONITORING OF LAND COVER IN DONGTING LAKE AREA BETWEEN 1995 2015 WITH LANDSAT IMAGERY
}

\author{
Yanyu Tao*, Guiwen Lan, Lixia She, Liyang Pang, Kaiwen Feng
}

Guangxi Key Laboratory of Spatial Information and Geomatics, College of Geomatics and Geoinformation, Guilin University of Technology, Guilin, Guangxi, China, 527656370@qq.com

KEY WORDS: Dongting Lake, Land Cover, Remote Sensing, Classification, Transfer Matrix, Landscape Pattern

\begin{abstract}
:
In this paper, the Landsat imagery of 1995, 2006 and 2015 is used to monitor land cover change in Dongting Lake area. Our study mainly focuses on five types of land cover: water body, wetland, built-up area, cropland and forest. The land cover change in the Dongting Lake area is comprehensively evaluated by using land cover transfer matrix, land cover change amplitude, and landscape pattern indexes. Our study shows that: (1) the cropland area increased from $48.58 \%$ in 1995 to $53.61 \%$ in 2006, then decreased to $48.85 \%$ in 2015; (2) different from the trend of cropland, the area of water body and wetland decreased in 2006; (3) the forest area steadily increased, to 2015, and there was an increase of 3.46\% during 1995-2015, due to artificial afforestation in the lake area. In terms of the landscape pattern, the landscape fragmentation decreased and the patch connectivity increased.
\end{abstract}

\section{INTRODUCTION}

Land cover is an important factor for ecosystems and living surroundings which affects the global climate, species diversity, the balance of ecosystems and the sustainable development of mankind and nature (Shili LI et al., 2008). In recent years, various studies have been conducted in the analyses of land use/land cover (LULC). For example, Jiyuan Liu et al. proposed an index called land cover change amplitude to characterise large-scale land use change(Jiyuan LIU and Buheaosier, 2000); Yunqiang Zhu(Yunqiang ZHU, Jiulin SUN, 2006) gave a detailed introduction to the technical procedure of land use change monitoring by using annual remote sensing images. There are some studies that mainly focus on environmental change in Dongting Lake area, such as Rengdong LI (2003) and Shuqing Zhao (2003). Rengdong LI et al. (Rengdong LI et al., 2003) analysed the variation characteristics of land use change from 1970s to 1990s in Dongting Lake area by extracting geographic features of land types from the Landsat MSS images produced in this period; Shuqing Zhao et al. (Shuqing ZHAO et al., 2003) analysed the main driving factors influencing the change of land use and landscape structure in Dongting Lake area based on Landsat images of years 1978, 1989 and 1998. However these studies largly used a single indicator to quantify the impacts of human activities on LULC, and most of the research time before 2000. To comprehensively analyse the LULC change of last two decades in Dongting Lake area, we use the Landsat imagery of years 1995, 2006 , 2015, and land classification map of this area, to analyse the land cover change, with land cover transfer matrix, land cover change amplitude and landscape pattern indexes.

\section{RESEARCH METHODS}

Exploring the changes in land cover need go through two steps: land cover extraction and analysis of land cover change.

\subsection{Land Cover Extraction}

The classification of LULC from remotely sensed imagery can be divided into two general image analysis approaches: pixel-based image analysis and object-based image analysis (Duro D C et al., 2012; Qiaojing QIAN et al., 2005). Pixelbased image analysis has manual visual interpretation and computer automatic classification. Computer automatic classification is divided into supervised classification and unsupervised classification, according to the classification demands to select suitable classification algorithm to extract land information from remote sensing image. For example, Lexiang QIAN (Lexiang QIAN, 2005) applied the maximum likelihood classifier (MLC) to extract land cover feature by combining spectral bands of Landsat images in false color synthesis (band2/3/4). Object-based image analysis is a subdiscipline of GIScience devoted to partitioning remote sensing imagery into meaningful image-objects, and assessing their characteristics through spatial, spectral and temporal scale (Blaschke T et al., 2008). It contains two steps: image segmentation and image information extraction (Zhihua LIANG and Yong LIU, 2015.). Compared to pixelbased image analysis, processing very large datasets is a formidable task for object-based image analysis methods. From a practical production standpoint, the setup and execution of object-based classifications were more labor intensive. Therefore pixel-based image analysis is more suitable for the land information extraction.

There are several ways to implement supervised classification, the common methods include decision trees (DTs), a neural network classifier, and the maximum likelihood classifier (MLC), support vector machine (SVM). According to the research of Huang et al. (C. Huang et al., 2002), as a kind of supervised classification, the method based on SVM classification parameters could give more stable overall accuracies than some other methods. In this research, it is used to extract the land cover feature.

\footnotetext{
* Corresponding author
} 


\subsection{Land Cover Change}

Land cover change includes the change of land cover type, the change of land use degree index and the spatial variation of land use structure. With reference to the methods used by Yewei XIE(Yewei XIE, et al., 2010), Rui LIU(Rui LIU and Daolin ZHU, 2010) and Linna WU(Linna WU, et al., 2014), this paper analyses land cover change from three aspects: land cover transfer matrix, land cover change amplitude and landscape pattern indexes. The transfer matrix calculates the transition probability by computing the conversion and unchanged areas of different land types. The other two indicators are calculated as follows.

\subsection{Land Cover Change Amplitude}

Land cover change amplitude describes the rate of land change quantitatively, and can reflect the dramatic change of land cover in the study area (Jiyuan LIU and Buheaosier, 2000; Fuhui LIU, 2009). Land cover change amplitude is composed of two indicators: the change amplitude of a single land cover and change amplitude of synthesis land cover.

(1) Change amplitude of synthesis land cover characterises the conversion rate of all land types in study area. It can be computed by Equation (1).

$$
L C=\frac{\sum_{i}\left|U_{i}^{k+1}-U_{i}^{k}\right|}{2 \sum_{i} U_{i}^{k}} \times \frac{1}{T} \times 100 \%
$$

(2) Change amplitude of single land cover aid to characterise the conversion rate of a single land type in study area. It can be computed by Equation (2).

$$
L C_{i}=\frac{U_{i}^{k+1}-U_{i}^{k}}{U_{i}^{k}} \times \frac{1}{T} \times 100 \%
$$

where $\quad L C=$ change amplitude of synthesis land cover $L C_{i}=$ change amplitude of single land cover $U_{i}^{k}=$ the area of land type $i$ at preliminary stage $U_{i}^{k+1}=$ the area of land type $\mathrm{i}$ at end of study time $T=$ study time (unit: year)

From Equation (1) and (2), change amplitude of synthesis land cover can compensate for partial land areas change in the study area, which disguise the actual situation of land change, and are not suitable for this study. Whereas change amplitude of a single land cover shows the change rate of a single type, it is more suitable for analyses land cover change.

\subsection{Landscape Pattern Index}

The design of landscape pattern depends on the element type, numbers and spatial distribution and configuration of landscape. It is the concrete manifestation of landscape heterogeneity, and includes the effects of various ecological processes on different scales (O'NEILL R V et al., 1988; II B T et al., 1990). Our research through calculating the Largest patch index (LPI), Shannon's diversity index (SHDI) and Shannon's evenness index (SHEI), Contagion index (CONTAG), Interspersion and Juxtaposition index (IJI) to describe the change of Dongting Lake land cover landscape pattern. They can be calculated by following formula:

$$
\begin{aligned}
& L P I=\frac{M A X_{j=1}^{n}\left(a_{i j}\right)}{A}(100) \\
& \text { SHDI }=-\sum_{i=1}^{m}\left(P_{i} \ln P_{i}\right) \\
& \text { SHEI }=\frac{-\sum_{i=1}^{m}\left(P_{i} \ln P_{i}\right)}{\ln m} \\
& \text { CONTAG }=\left[1+\frac{\sum_{i=1}^{m} \sum_{k=1}^{m}\left[\left(p_{i}\right)\left(\frac{g_{i k}}{\sum_{k=1}^{m} g_{i k}}\right)\right]\left[\ln \left(p_{i}\right)\left(\frac{g_{i k}}{\sum_{k=1}^{m} g_{i k}}\right)\right]}{2 \ln (m)}\right](100) \\
& I J I=\frac{-\sum_{i=1}^{m} \sum_{k=i+1}^{m}\left[\left(\frac{e_{i k}}{E}\right) \cdot \ln \left(\frac{e_{i k}}{E}\right)\right]}{\ln (0.5[m(m-1)])}(100) \\
& \text { where } \quad a_{i j}=\text { the area of plaque (unit: } \mathrm{m}^{2} \text { ) } \\
& A=\text { landscape area } \\
& P_{i}=\text { the percentage of area occupied by the i type }
\end{aligned}
$$

\section{SURVEY OF THE RESEARCH AREA AND DATA PROCESSING}

\subsection{Survey of Research Area}

Dongting Lake area $\left(28^{\circ} 30^{\prime} \mathrm{N} \sim 30^{\circ} 20^{\prime} \mathrm{N}\right.$ and $110^{\circ} 40^{\prime} \mathrm{E} \sim$ $\left.113^{\circ} 10^{\prime} \mathrm{E}\right)$, located in the south coast of Jingjiang, is part of the Yangtze River watershed in China. Dongting Lake connects several rivers, the four biggest tributaries are $\mathrm{Li}$ River, Yuan River, Zi River and the Xiang River (Lotz T et al., 2017). Dongting Lake area covers approximately 1.878 million square kilometres, which is an important commodity grain base in China. Based on the correlational research, our research focuses on Yueyang city, Huarong county, Yueyang county, Miluo city, Xiangyin county, Changde city, Hanshou county, Anxiang county, Yiyang city, Yuanjiang city, Nanxian county and Taojiang county.

\subsection{Data Sources and Processing}

Land cover change analysis based on scenes from Landsat 5 Thematic Mapper(TM) in 1995 and 2006, and Landsat 8 Operational Land Imager (OLI) in 2015. Data quality controlling is an important index for land cover extraction, it depend on two conditions: acquired time and cloud covers. The time of remote sensing images were acquired between late October and early February of the following year. In addition, only images which less than $10 \%$ cloud covers were employed. Under these conditions, ground water levels fall, making it easier to distinguish different land cover types, and the influence of cloud on the image is avoided as much as possible, and it is easier to extract land cover information. 
Before land cover classification, a series of pro-processing operations for Landsat image are necessary, such as radiometric calibration, atmospheric correction and image registration (Yingshi ZHAO et al., 2004; Anxi MEI et al., 2001). These operations are able to avoid geometric distortion and radiation distortion effectively. Refer to the demonstration of land classification system put forward by Shuqing Zhao (Shuqing ZHAO et al., 2002), Lingdong Meng (Lingdong MENG, 2009) and Xiping Yuan (Xiping YUAN and Shu GAN, 1999), we divide the study area into five types of land: water body, wetland, built-up area, cropland and forest.

\section{RESULTS AND DISCUSSION}

A supervised signature extraction with support vector machine algorithm was employed to extract land cover information of Dongting Lake area. The land use/land cover maps for 1995, 2006 and 2015 were produced from Landsat images and displayed in Figure 1 3.

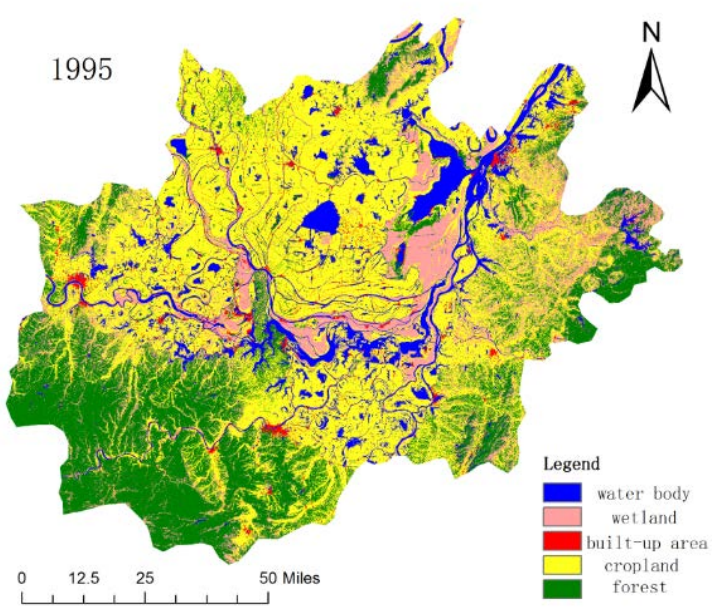

Figure 1. LULC map of Dongting Lake area in 1995

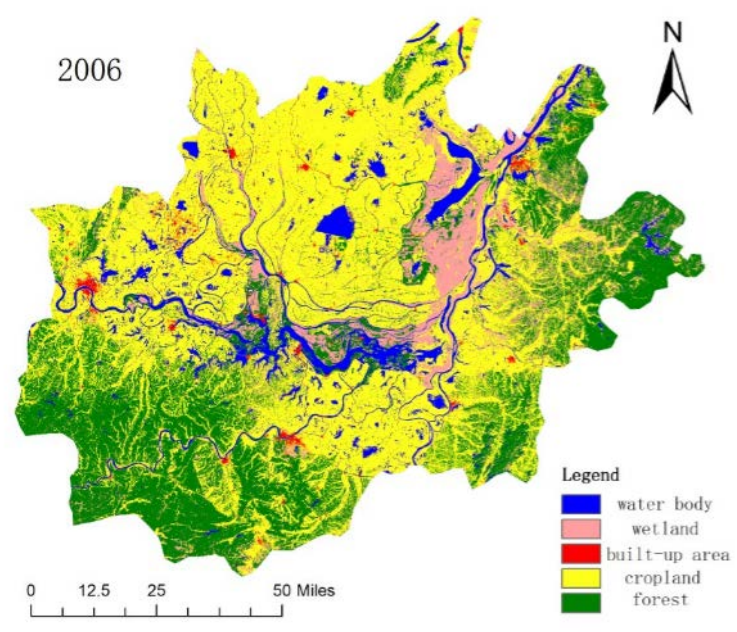

Figure 2. LULC map of Dongting Lake area in 2006

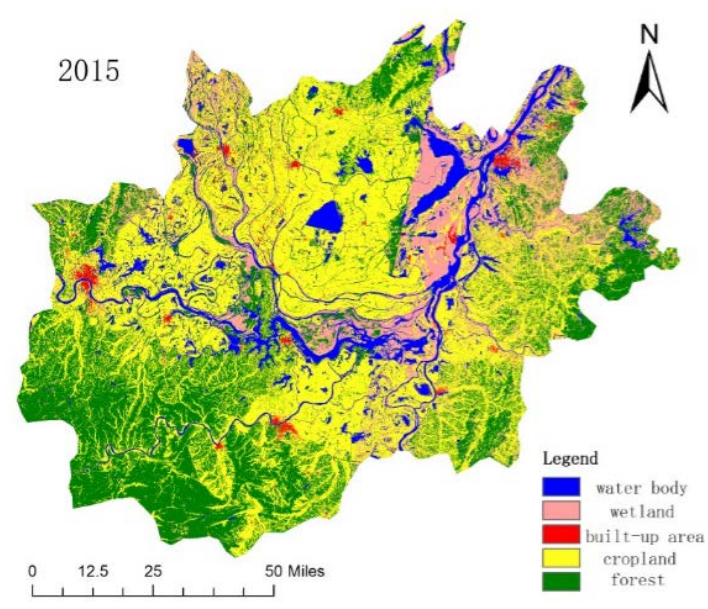

Figure 3. LULC map of Dongting Lake area in 2015

The proportion of each land cover type in lake area at three periods by calculating their grid numbers and grid size in LULC map (Figure 1 3), it shows in Figure 4. Cropland and forest occupy a large proportion in lake area, of which cropland areas about $50 \%$, the agricultural in the lake area has a prominent place. The area of forest occupied $24.21 \%$ of the total area in 1995, and increased year by year in the last 20 years. Water body and wetland are suitable for birds and waterfowl survival, and their areas have the same trend in the last two decades, the percentage of the area is about $10 \%$. The built-up area showed a declining trend, falling from $2.59 \%$ in 1995 to $1.31 \%$ in 2015 .

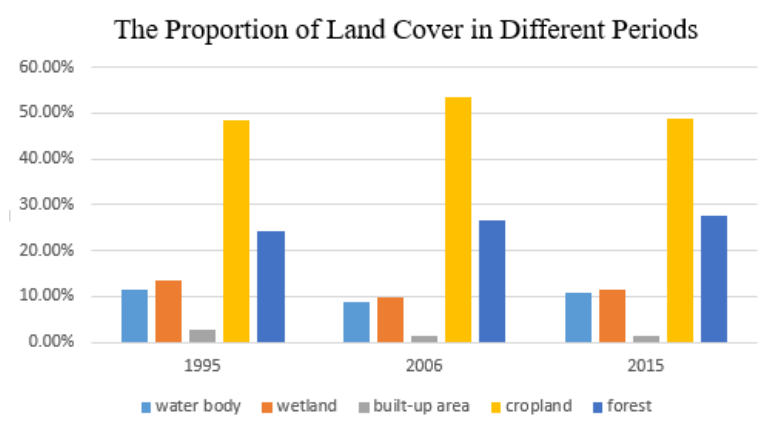

Figure 4. The proportion of land cover in different periods

\subsection{Analysis of Land Cover Transfer}

Table 1 and Table 2 show two stages of land cover transfer matrix from 1995 to 2006 and 2006 to 2015.

From 1995 to 2006, cropland and forest kept high land retention rate, which are relatively stable land types. The portion of cropland transforms into water body and wetland arrived at $6.48 \%$ and $8.55 \%$ because of the natural land cover succession. Water body is mainly converted into cropland, and conversion rate is $30.59 \%$. During the same period, the proportion of wetland converted to cropland arrived at $36.92 \%$, but its retention rate is only $30.59 \%$. From LULC map of Dongting Lake area in 1995 and 2006(Figure 1 and Figure 2), it was found that most lake areas have shrunk in that period, and water body is sparsely distributed in the northern lake district. New cropland replaced the position of the water body and wetland. The first reason for these 
phenomena is the annual rainfall decreased, which lead to falling of the water level and wetland atrophy; Second, there is still reclaiming parts of lakes for farmland in the lake area, occupying a large area of wetlands and water bodies. About $49.4 \%$ of built-up area converted into cropland. This is because built-up area in the remote sensing image belongs to mixed pixel, it will be confused with other land types in the classification. Some of built-up area merge into the cropland, lead to low accuracy in built-up area classification results, so there is no detailed analysis here.

From 2006 to 2015, the proportion of other land types transferred to the cropland decreased. During this period, water body retention rate increased, and reduces the probability of water body into cropland. As water body areas increase, the retention rate of wetland has increased by $9.38 \%$. The transfer rate of cropland to water body increased from
$1.93 \%$ to $5.46 \%$. Different from previous years, cropland and forest are gradually transformed into water body and wetland, which indicated the large-scale reclamation activity in Dongting Lake area was phased out. The area of water body and wetland will gradually recover. The reservation rate of forest was reduced to $72.63 \%$, at the same time, the ratio of other land cover types contribute to forest increased. As a whole, forest areas have maintained a growth status in the last two decades, thanks to the ecological restoration of local reforestation. The entire forest maintained about $70 \%$ retention rate and the transfer rate of forest land to cropland got to about $17 \%$ in the last two decades. Judging by these changes, the consumption of forest in Dongting Lake area is high. The probability of forest conversion to farmland is maintained at a steady value, which shows some forest was artificially reclaimed for cropland.

\begin{tabular}{cccccc}
\hline & \multicolumn{5}{c}{2006} \\
\cline { 2 - 5 } 1995 & Water body & Wetland & Built-up area & Cropland & Forest \\
\hline Water body & 61.24 & 2.26 & 2.07 & 30.59 & 3.84 \\
Wetland & 1.01 & 35.93 & 0.64 & 36.92 & 25.52 \\
Built-up area & 14.94 & 6.37 & 19.76 & 49.40 & 9.52 \\
Cropland & 1.93 & 6.48 & 1.13 & 81.91 & 8.55 \\
Forest & 1.16 & 5.43 & 0.41 & 17.23 & 75.77 \\
\hline
\end{tabular}

Table 1. Land cover transfer matrix of Dongting Lake from 1995 to 2006(\%)

\begin{tabular}{cccccc}
\hline & \multicolumn{5}{c}{2015} \\
\cline { 2 - 5 } 2006 & Water body & Wetland & Built-up area & Cropland & Forest \\
\hline Water body & 77.32 & 1.21 & 0.59 & 10.88 & 10.01 \\
Wetland & 5.19 & 45.31 & 1.23 & 29.03 & 19.24 \\
Built-up area & 11.32 & 9.52 & 30.32 & 37.27 & 11.57 \\
Cropland & 5.46 & 8.12 & 1.19 & 75.02 & 10.20 \\
Forest & 1.32 & 9.54 & 0.20 & 16.31 & 72.63 \\
\hline
\end{tabular}

Table 2. Land cover transfer matrix of Dongting Lake from 2006 to 2015(\%)

\subsection{Analysis of Land Cover Change Amplitude}

According to land cover property information at three periods, we calculated their land cover change amplitude, the result are show in Table3.

Between 1995 and 2006, the change amplitude of built-up area is largest. It embodied in the pace of construction in the area has accelerated, and some built-up area plaques which dispersed in cropland or the edge of wetland disappeared. The change amplitude of water body and wetland are second to built-up area Due to an autumn drought in 2006, lake areas decreased and some tributaries of Dongting Lake is shrinking. As a whole, the change of water body and wetland kept a negative trend.
Between 2006 and 2015, the change amplitude of water body is largest, followed by wetland, built-up area, cropland and forest. That proves the wetland ecosystem in Dongting Lake maintains a good development trend. Water body areas growth driving wetland areas growth. In the past ten years, the effect of returning farmland to the lake has been gradually highlighted. Part of the land reclaimed into farmland is gradually restored to water and wetland. So the agricultural acreage has been reduced.

In the last two decades, the largest change take place in the built-up area, next is the forest, wetland, water, cropland. During this period, the main reason for the forest areas growth is extension of artificial forest with local government support, poplar trees with economic value and other diversified forest land instead of a barren wasteland.

\begin{tabular}{cccc}
\hline Land type & $1995 \sim 2006$ & $2006 \sim 2015$ & $1995 \sim 2015$ \\
\hline Water body & -2.13 & 2.54 & -0.29 \\
Wetland & -2.49 & 2.13 & -0.67 \\
Built_up area & -3.90 & -1.27 & -2.47 \\
Cropland & 0.94 & -0.99 & 0.03 \\
Forest & 0.89 & 0.46 & 0.72 \\
\hline
\end{tabular}

Table 3. Dongting Lake area change amplitude of single land cover 


\subsection{Analysis of Landscape Pattern}

Landscape pattern index calculation results of Dongting Lake area in Table 4

Figure 4 and Table 4 show that cropland is the most stable and important landscape type in the lake area, mainly distributed in the north and middle of the lake area, which maintains the stability of the whole regional ecosystem. In the last two decades, LPI index of Dongting Lake reached its peak in 2006. That shows the dominance of cropland in the lake area has risen and connectivity enhance. By comparing LULC map in 1995 and 2006 (Figure 1 and Figure 2), cropland occupied the original water body and wetland in 2006. This is the reason for the expansion of cropland patch and connectivity enhance.

Until to 2015, water body and wetland restored from drought and reclamation, parts of cropland was transformed into the water body and wetland, so LPI index fell. SHDI index drop during last two decades shows that land fragmentation index decreased and the single plaque area of forest and cropland increased. The drop of SHEI indicates the dominance index of Dongting Lake area rose. Forest as a dominant land type in the lake region, the broken patches was communicated to larger plaques (as show in Figure 3). It plays a supporting role in the ecosystem of the Lake District. CONTAG is less than 60 and IJI decreased year by year, landscape pattern of Dongting Lake area performance as plaque numbers decreased and average plaque area growth. Through the analysis of landscape pattern, we found some change characteristics: (1)the overall fragmentation index of Dongting Lake area has been fell in the last two decades, some broken plaques of water body and wetland have disappeared due to human activities and natural drought; (2) the fragmentation index of forest area in the eastern and western lake area is decreased affected by artificial afforestation; (3) some small pieces of water and wetland plaque are replaced by cropland in the northern lake area, which makes the cropland connectivity increased.

\begin{tabular}{cccccc}
\hline Year & LPI & SHDI & SHEI & CONTAG & IJI \\
\hline 1995 & 6.61 & 1.30 & 0.81 & 45.88 & 81.49 \\
2006 & 16.37 & 1.19 & 0.74 & 51.55 & 75.52 \\
2015 & 8.23 & 1.25 & 0.78 & 47.19 & 73.75 \\
\hline
\end{tabular}

Table 4. Landscape index of land-cover in Dongting Lake area

\section{CONCLUSIONS}

In this study we analyzed the land cover dynamic change in Dongting Lake area from four aspects: land cover space distribution, transfer matrix of land cover, land cover change amplitude and landscape pattern index. We used Landsat imagery of 1995, 2006 and 2015 in Dongting Lake area and the combination of ENVI and ArcGIS to extract the land cover information.

The temporal and spatial variation of land cover in Dongting Lake area is striking in the last two decades. During the period from 1995 to 2006, the land cover change shows that cropland areas increase and connectivity enhance, some broken patches of water body disappeared in the study area. The reduction of rainfall resulted in the shrinkage of the lake and wetland area, and the waterfowl habitats in the lake area were affected too.

During the period from 2006 to 2015, the trend of land cover change in Dongting Lake area has been changed. The area of cropland didn't grow in this period. Part of cropland is converted into water body, wetland and forest. After stopping reclaim land from lakes, water body and wetlands maintain healthy development under natural conditions, also the wetland ecological pattern improved at the same time. The forest land areas increased in the mass due to ecological restoration.

There are some uncertain factors in our study, for example, the built-up area belongs to mixed pixels, which are easy to be mixed with the pixels of water body and cropland. Therefore, it is necessary to combine the field investigation with statistical data to analyze the spatial and temporal changes in the built-up area.

\section{REFERENCES}

Anxi MEI, Wanglu Peng, Qiming QING, 2001. Introduction to Remote Sensing. Higher Education Press, Beijing, pp. 193201.

Blaschke T, Lang S, Hay G J, 2008. Object-Based Image Analysis: Spatial Concepts for Knowledge-Driven Remote Sensing Applications. Springer Publishing Company, Incorporated, 65(1), pp. 2-16.

C. Huang, L. S. Davis, J. R. G, 2002. Townshend. An assessment of support vector machines for land cover classification. International Journal of Remote Sensing, 23(4), pp. 725-749.

Duro D C, Franklin S E, Dubé M G, 2012. A comparison of pixel-based and object-based image analysis with selected machine learning algorithms for the classification of agricultural landscapes using SPOT-5 HRG imagery. Remote Sensing of Environment, 118(6), pp. 259-272.

Fuhui LIU, 2009. A study on dynamic monitoring of landcover change in Yongding district of Zhangjiajie based on remote sensing. Central South University, Changsha.

II B T, KASPERSON R E, MEYER W B, et al., 1990. Two types of global environmental change: definitional and spatial. Global Environmental Change, 1(1), pp. 14-22.

Jiyuan LIU, Buheaosier, 2000. Study on spatial-temporal feature of modern landuse change in China: using remote sensing techniques. Quaternary Sciences, 20(03), pp. 229239. 
Lexiang QIAN, 2005. Influence of land cover change on land surface temperature in Zhujiang delta. Acta Geografica Sinica, 60(5), pp. 761-770.

Lingdong MENG, 2009. Research on the land use/cover change of single back area in Dongting Lake--take Qianlianghu for example. Huazhong Agricultural University, Wuhan.

Linna WU, Shengtian YANG, Xiaoyan LIU, et al., 2014. Response analysis of land use change to the degree of human activities in Beiluo River basin since 1976. Acta Geografica Sinica, 69(1), pp. 54-63.

Lotz T, Opp C, He X, 2017. Factors of runoff generation in the Dongting Lake basin based on a SWAT model and implications of recent land cover change. Quaternary International.

O'NEILL R V, KRUMMEL J R, GARDNER R H, et al., 1988. Indices of landscape pattern. Landscape Ecology, 1(3), pp. 153-162.

Qiaojing QIAN, Rui XIE, Lei ZHANG, et al., 2005. Land cover extraction based on object oriented analysis. Remote Sensing Technology and Application, 20(3), pp. 338-342.

Rengdong LI, Defang ZHUANG, Hongzhi WANG, et al., 2003. Spatial-temporal changes of the land use/cover in the Dongting-lake area during the last twenty years. Progress in Geography, 22(02), pp.164-169+222.

Rui LIU, Daolin ZHU, 2010.Methods for detecting land use changes based on the land use transition matrix. Resources Science, 32(8), pp.1544-1550.
Shili LI, Guotao TANG, Xiansheng DONG, et al., 2008. A research on worldwide land utilization and land cover change. Journal of Guangxi Agriculture, 2008(03), pp.42-44.

Shuqing ZHAO, Jingyun FANG, Anping CHEN, et al., 2002. Land use/cover changes in Dongting lake area between 1955 1998. Resources and Environment in the Yangtze Basin, 11(06), pp. 536-542.

Shuqing ZHAO, Jingyun FANG, Anping CHEN, et al., 2003. Dynamics of waterfowl habitats in the eastern Dongting lake nature reserve between 1989 and 1998. Journal of Natural Resources, 18(06), pp. 726-733.

Xiping YUAN, Shu GAN, 1999. Comparison and analysis on land cover remote sensing monitoring and typical classification system. Journal of Yunnan Polytechnic University, 15(04), pp.7-10.

Yewei XIE, Zhaogang LIU, Jun ZHAO,et al,2010.Analysis of land use dynamic in typical black soil region based on GIS and RS-A case study of Hailun county. Scientia Geographica Snica, 30(3), pp. 428-434.

Yingshi ZHAO, Shen ZHANG, Dahe QING, 2004. Principle and Method of Remote Sensing Application Analysis. The Science Publishing Company, Beijing, pp.121-137.

Yunqiang ZHU, Jiulin SUN, 2006. Dynamic monitoring of land use through remote sensing technology:--A case study in Anning district, Lanzhou city. Resources Science, 28(02), pp.82-87.

Zhihua LIANG, Yong LIU, 2015. Land use/land cover changes and mechanics at the southern boundary area of Tengger desert in the past 20years-A case study for Bingcaowan,Gulang county,Gansu province,china. Remote Sensing Technology and Application, 30(2), pp. 383-390. 